$\begin{array}{cc}\text { ACADEMIA ROMÂNĂ } & \text { Rev. Roum.Chim., } \\ \text { Revue Roumaine de Chimie } & \text { 2019, 64(2), 183-189 } \\ \text { http://web.icf.ro/rrch/ } & \text { Doi: 10.33224/rrch.2019.64.2.08 }\end{array}$

\title{
QSPR STUDY ON THE BOILING POINTS OF ALIPHATIC ESTERS USING THE ATOM-TYPE-BASED AI TOPOLOGICAL INDICES
}

\author{
Bahare OSAGHI and Fariba SAFA* \\ Department of Chemistry, Rasht Branch, Islamic Azad University, Rasht, I. R. Iran
}

Received April 1, 2018

\begin{abstract}
In this work, normal boiling points (NBPs) for a group of aliphatic esters were modeled using a combination of the modified $\mathrm{Xu}\left({ }^{\mathrm{m}} \mathrm{Xu}\right)$ and the atom-type-based AI topological indice. The multiple linear regression model consisting of ${ }^{\mathrm{m}} \mathrm{Xu}, \mathrm{AI}\left(-\mathrm{CH}_{3}\right)$ and $\mathrm{AI}(-\mathrm{O}-)$ showed the squared correlation coefficient, Fisher ratio and standard error values of $0.994,6705.7$ and 4.54 , respectively. Statistical validity of the model was verified by the external validation technique. Based on the results, fraction contribution of the topological indices entered the model decreased in the order of ${ }^{\mathrm{m}} \mathrm{Xu}>\mathrm{AI}\left(-\mathrm{CH}_{3}\right)>\mathrm{AI}(-\mathrm{O}-)$ showing that NBPs of aliphatic esters are mainly dominated by molecular size, and degree of branching and polarity of the molecules have smaller contributions to the normal boiling points.
\end{abstract}

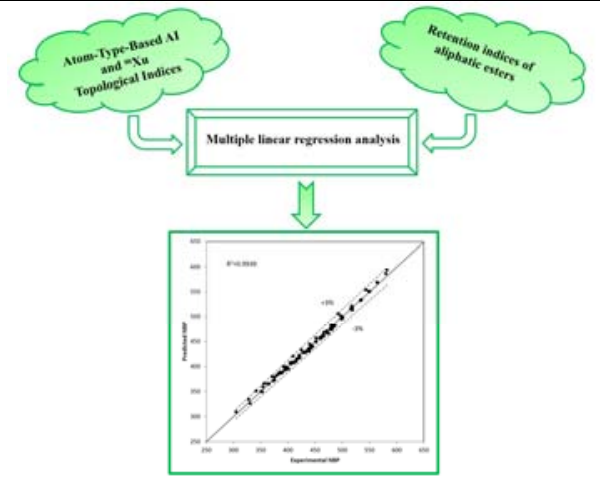

\section{INTRODUCTION}

Quantitative structure-property relationship (QSPR) modeling is one of the most effective approaches for estimation of a variety of physicochemical $^{1-6}$ and toxicological properties ${ }^{7-9}$ which can provide significant information on the molecular features determining the properties of chemical compounds. The first step in a QSPR study is quantifying chemical structure of the molecules by numerical codes named descriptors that can show structural similarity and diversity of the molecules. Among the descriptors, topological indices have found major popularity in QSPR studies since they can be directly derived from the structure of the molecules on the basis of graph theory without any experimental effort. However, the conventional topological indices such as the well-known molecular connectivity index ${ }^{10}$ characterize a molecule as a whole (i.e., molecular size or shape). Additionally, the indices give no information on compounds with multiple bonds and heteroatoms. Unlike the conventional topological indices, the atomic level topological indices describe the structural information of a molecule at the atomic leve and code the structural environment of each atom type in a molecule. Kier et al. first introduced the concept of atom-type-based topological index, i.e. the so-called electrotopological state index. ${ }^{11}$ Ren proposed a set of atomic-based AI topological indices that along with $\mathrm{mXu}$ index have been successfully used in developing high quality models for estimation of the physicochemical properties such as normal boiling points, molar refractions, van der Waals' constants, Pitzer's acentric factors, etc. ${ }^{12-16}$ In a previous paper, our group reported QSPR study of standard formation enthalpies of acyclic alkanes using the AI topological indices. ${ }^{17}$ Nevertheless, the use of AI indices in prediction of NBPs of esters has been largely neglected.

\footnotetext{
*Corresponding author: Safa@iaurasht.ac.ir; Safa_f@yahoo.com
} 
The main goal of the present work was to further verify the potential of the atom-type-based AI topological indices as effective descriptors in prediction of NBPs of aliphatic esters. Moreover, the influence of different structural features and atomic groups on the normal boiling points of the model compounds is illustrated. As far as we are aware, this is the first report on QSPR study of aliphatic esters in which the atom-type-based AI topological indices are employed.

\section{EXPERIMENTAL}

\section{Data set and regression analysis}

Experimental data of NBPs for some aliphatic esters including $\mathrm{C} 2-\mathrm{C} 16$ linear and branched molecules were taken from the report of Brown and Stein ${ }^{18}$ One compound was not modeled in this study, as its structure prohibited accurate modeling of structure-boiling point relationship. Table 1 presents model compounds and the experimental NBP values in the range of 304.70 to $582.00 \mathrm{~K}$.

Table 1

Experimental and predicted normal boiling points of aliphatic esters

\begin{tabular}{|c|c|c|c|c|c|c|c|}
\hline No. & Compound & $\begin{array}{l}\mathrm{NBP}_{\text {exp }} \\
(\mathrm{K})\end{array}$ & $\begin{array}{c}\mathrm{NBP}_{\text {pred }} \\
(\mathrm{K})\end{array}$ & No. & Compound & $\begin{array}{l}\mathrm{NBP}_{\text {exp }} \\
(\mathrm{K})\end{array}$ & $\begin{array}{c}\mathrm{NBP}_{\text {pred }} \\
(\mathrm{K})\end{array}$ \\
\hline 1 & Methyl formate & 304.70 & 309.85 & 44 & pentyl propionate & 441.80 & 437.15 \\
\hline 2 & Methyl acetate & 330.00 & 326.94 & 45 & propyl pentanoate & 440.70 & 435.56 \\
\hline 3 & Ethyl formate & 327.50 & 334.83 & 46 & propyl 3-methylbutanoate & 429.00 & 428.63 \\
\hline 4 & n-propyl formate & 354.10 & 359.08 & 47 & methyl 4-methylhexanoate & 439.00 & 430.79 \\
\hline 5 & Isopropyl formate & 341.40 & 351.62 & 48 & tert-butyl butanoate & 409.40 & 420.32 \\
\hline 6 & Methyl propionate & 353.00 & 349.48 & 49 & 2-ethylbutyl acetate & 432.00 & 427.78 \\
\hline 7 & Ethyl propionate & 372.20 & 371.67 & 50 & 1,3-dimethylbutyl acetate & 420.70 & 422.83 \\
\hline 8 & Isopropyl acetate & 362.00 & 366.31 & 51 & methyl n-octanoate & 466.10 & 460.93 \\
\hline 9 & $\begin{array}{l}\text { Methyl 2- } \\
\text { methylpropionate }\end{array}$ & 365.00 & 365.06 & 52 & ethyl heptanoate & 461.70 & 457.88 \\
\hline 10 & Butyl formate & 379.70 & 382.65 & 53 & 3-methylbutyl butanoate & 452.20 & 449.16 \\
\hline 11 & Ethyl butanoate & 394.20 & 393.52 & 54 & heptyl acetate & 464.00 & 462.41 \\
\hline 12 & Butyl acetate & 399.10 & 396.57 & 55 & pentyl butanoate & 451.75 & 456.92 \\
\hline 13 & ethyl 2-methylpropionate & 385.70 & 386.39 & 56 & butyl pentenoate & 460.00 & 455.74 \\
\hline 14 & 2-methylpropyl acetate & 390.40 & 389.30 & 57 & $\begin{array}{l}\text { 2-methylpropyl 3- } \\
\text { methylbutanoate }\end{array}$ & 444.35 & 441.66 \\
\hline 15 & methyl pentanoate & 401.20 & 395.46 & 58 & hexyl propionate & 458.65 & 458.08 \\
\hline 16 & propyl propionate & 395.70 & 393.89 & 59 & octyl formate & 471.00 & 471.06 \\
\hline 17 & methyl 3-methylbutanoate & 389.70 & 388.15 & 60 & 1,4-dimethylpentyl acetate & 440.00 & 444.76 \\
\hline 18 & Isopropyl propionate & 383.00 & 386.54 & 61 & ethyl n-octanoate & 480.20 & 478.53 \\
\hline 19 & 1,1-dimethylethyl acetate & 370.70 & 380.05 & 62 & 1-octyl acetate & 483.20 & 481.74 \\
\hline 20 & 3-methylbutyl formate & 397.40 & 398.68 & 63 & $\begin{array}{l}\text { 3-methylbutyl 3- } \\
\text { methylbutanoate }\end{array}$ & 465.85 & 462.24 \\
\hline 21 & 1-methylpropyl acetate & 385.40 & 388.87 & 64 & methyl nonanoate & 486.70 & 481.75 \\
\hline 22 & methyl pivalate & 375.05 & 378.84 & 65 & 2-ethylhexyl acetate & 472.20 & 466.73 \\
\hline 23 & methyl n-hexanoate & 422.20 & 417.81 & 66 & butyl hexanoate & 480.89 & 474.17 \\
\hline 24 & n-pentyl acetate & 420.70 & 418.66 & 67 & hexyl 2-methylpropionate & 472.00 & 470.05 \\
\hline 25 & ethyl 3-methylbutanoate & 407.90 & 408.24 & 68 & heptyl propionate & 483.19 & 478.57 \\
\hline 26 & ethyl n-pentanoate & 415.90 & 415.32 & 69 & pentyl pentanoate & 479.00 & 475.70 \\
\hline 27 & 2-propyl butanoate & 403.70 & 407.59 & 70 & methyl decanoate & 497.20 & 502.11 \\
\hline 28 & n-propyl butanoate & 416.00 & 414.69 & 71 & ethyl nonanoate & 500.15 & 498.77 \\
\hline 29 & 2-methylbutyl acetate & 414.00 & 409.17 & 72 & octyl propionate & 501.00 & 498.64 \\
\hline 30 & 2-methylpropyl propionate & 410.00 & 408.54 & 73 & nonyl acetate & 497.00 & 501.85 \\
\hline 31 & n-hexyl formate & 427.20 & 427.91 & 74 & propyl octanoate & 499.58 & 496.61 \\
\hline 32 & 1-methylbuthyl acetate & 408.00 & 408.60 & 75 & heptyl butanoate & 499.00 & 496.54 \\
\hline
\end{tabular}


Table 1 (continued)

\begin{tabular}{|c|c|c|c|c|c|c|c|}
\hline 33 & 1-methylpropyl propionate & 406.20 & 406.29 & 76 & butyl heptanoate & 499.30 & 495.41 \\
\hline 34 & 1,1-dimethylpropyl acetate & 396.65 & 399.42 & 77 & hexyl pentanoate & 499.50 & 495.37 \\
\hline 35 & propyl 2-methylpropionate & 412.00 & 407.87 & 78 & 1,3,5-trimethylhexyl acetate & 474.65 & 466.01 \\
\hline 36 & 2-pentyl acetate & 408.00 & 408.60 & 79 & ethyl decanoate & 518.20 & 518.63 \\
\hline 37 & $\begin{array}{l}\text { 1,1-dimethylethyl } \\
\text { propionate }\end{array}$ & 391.50 & 399.79 & 80 & hexyl hexanoate & 518.58 & 513.46 \\
\hline 38 & 3-pentyl acetate & 407.00 & 405.75 & 81 & decyl acetate & 517.15 & 521.57 \\
\hline 39 & n-hexyl acetate & 442.20 & 440.02 & 82 & octyl butanoate & 515.40 & 516.10 \\
\hline 40 & n-butyl butanoate & 437.70 & 435.67 & 83 & heptyl pentanoate & 518.36 & 514.75 \\
\hline 41 & methyl heptanoate & 445.20 & 439.58 & 84 & 1-methylheptyl butanoate & 492.00 & 505.87 \\
\hline 42 & 2-methylpropyl butanoate & 430.00 & 428.57 & 85 & heptyl hexanoate & 534.12 & 532.96 \\
\hline 43 & 3-methylbutyl propionate & 433.90 & 429.99 & 86 & nonyl butanoate & 535.00 & 535.04 \\
\hline No. & Compound & $\begin{array}{c}\mathrm{NBP}_{\text {exp }} \\
(\mathrm{K})\end{array}$ & $\begin{array}{c}\mathrm{NBP}_{\text {pred }} \\
(\mathrm{K})\end{array}$ & No. & Compound & $\begin{array}{c}\mathrm{NBP}_{\text {exp }} \\
(\mathrm{K})\end{array}$ & $\begin{array}{c}\mathrm{NBP}_{\text {pred }} \\
(\mathrm{K})\end{array}$ \\
\hline 87 & pentyl octanoate & 533.36 & 533.05 & 104 & ethyl hexanoate & 441.20 & 436.80 \\
\hline 88 & hexyl heptanoate & 534.04 & 532.72 & 105 & 2-methylpropyl 2-methylpropionate & 420.70 & 421.69 \\
\hline 89 & decyl butanoate & 543.00 & 554.22 & 106 & 1-methylpropyl butanoate & 424.65 & 433.43 \\
\hline 90 & heptyl heptanoate & 550.36 & 551.09 & 107 & heptyl formate & 451.27 & 449.72 \\
\hline 91 & hexyl octanoate & 550.59 & 551.14 & 108 & propyl hexanoate & 458.70 & 456.23 \\
\hline 92 & heptyl octanoate & 563.80 & 569.06 & 109 & 3-methylbutyl 2-methylpropionate & 442.95 & 442.42 \\
\hline 93 & octyl heptanoate & 563.90 & 569.24 & 110 & $n$-hexyl $n$-butanoate & 478.25 & 477.13 \\
\hline 94 & octyl octanoate & 580.00 & 586.80 & 111 & butyl hexanoate & 477.50 & 474.17 \\
\hline 95 & ethyl acetate & 350.20 & 350.59 & 112 & 3-methylbutyl pentanoate & 466.00 & 468.50 \\
\hline 96 & methyl butanoate & 375.40 & 372.60 & 113 & propyl heptanoate & 481.09 & 476.59 \\
\hline 97 & tert-butyl formate & 355.70 & 366.25 & 114 & pentyl hexanoate & 498.00 & 495.01 \\
\hline 98 & $\begin{array}{l}\text { methyl 2- } \\
\text { methylbutanoate }\end{array}$ & 388.20 & 387.49 & 115 & methyl 2-butylhexanoate & 479.15 & 482.95 \\
\hline 99 & n-pentyl formate & 405.50 & 405.56 & 116 & butyl octanoate & 518.17 & 514.85 \\
\hline 100 & ethyl 2-methylbutanoate & 406.20 & 406.20 & 117 & octyl pentanoate & 534.75 & 533.81 \\
\hline 101 & $n$-butyl propionate & 418.70 & 415.75 & 118 & $n$-octyl hexanoate & 548.40 & 551.55 \\
\hline 102 & 3-methylbutyl acetate & 415.20 & 411.60 & 119 & ethyl tetradecanoate & 582.00 & 594.61 \\
\hline 103 & $\begin{array}{l}\text { 1-methylethyl 2-methyl } \\
\text { propionate }\end{array}$ & 393.90 & 399.77 & & & & \\
\hline
\end{tabular}

Linear regression analyses were performed using SPSS/PC software package. ${ }^{19}$ Criteria for selection of the best multiple linear regression (MLR) model were the statistics of squared correlation coefficient $\left(\mathrm{R}^{2}\right)$, adjusted correlation coefficient $\left(\mathrm{R}_{\text {adj }}^{2}\right)$, Fisher-ratio (F) and standard error of estimate (SE). Statistical validity of the model was tested using external validation method.20,21 by dividing the entire data set into five subsets, leaving out one subset as prediction set, and regenerating the model coefficients for the training set composed of the other four subsets. Then, the standard errors of calibration (SEC) and prediction (SEP) were employed to evaluate quality of the models.

\section{Descriptor generation}

Topological indices for aliphatic esters were drived from the molecular graph $\mathrm{G}=[\mathrm{V}, \mathrm{E}]$, where $\mathrm{V}$ and $\mathrm{E}$ symbolize the atoms of a molecule and the chemical bonds, respectively. The indices was calculated using the distance matrix, $\mathbf{D}=\left[\mathrm{d}_{\mathrm{ij}}\right]_{\mathrm{nxn}}$ and the vertex-adjacency matrix, $\mathbf{A}=\left[\mathrm{a}_{\mathrm{ij}}\right]_{\mathrm{nxn}}$ in which the elements $d_{i j}$ are the length of shortest path between vertex $i$ and vertex $j$ and the elements $a_{i j}$ are 1 , if atom si and $j$ are adjacent and and 0 otherwise. Also,. The sums over row $i$ or column $j$ of $\mathbf{A}$ and $\mathbf{D}$ matrices yields local vertex-degree $v_{i}$ and the distance sums $s_{i}$, respectively. The ${ }^{m} \mathrm{Xu}$ index for a molecule with $\mathrm{n}$ atoms is defined as: ${ }^{12}$

$$
X u=n^{1 / 2} \log \left(\sum_{i=1}^{n} v_{i} s_{i}^{2} / \sum_{i=1}^{n} v_{i} s_{i}\right)
$$

where the sum is over all $\mathrm{i}$ vertices in graph. For any atom $\mathrm{i}$ that belongs to jth atom type in the graph, corresponding AI index is defined as: ${ }^{13}$ 


$$
A I_{i}(j)=1+\phi_{i}(j)=1+\left(v_{i}(j) s_{i}^{2}(j) / \sum_{i=1}^{n} v_{i} s_{i}\right)
$$

where $\phi_{\mathrm{i}}(\mathrm{j})$ is a perturbing term reflecting the effect of the structural environment of the ith atom on its topological index value and the topological index for jth atom-type in a graph, $A I(j)$, is the sum of all $A_{i}(j)$ values of the same atom type in the graph. Moreover, for differentiation of the hetero atoms and multiple bonds, the degree of vertex, $\mathrm{v}^{\mathrm{m} 14}$ based on the valence connectivity of Kier-Hall ${ }^{22}$ is used.

\section{RESULTS AND DISCUSSION}

\section{Linear regression models} for normal boiling points of aliphatic esters

In the first step of the study, simple linear regression model was developed for NBPs using ${ }^{\mathrm{m}} \mathrm{Xu}$ index alone. Specifications of the model found for the data set along with the statistical parameters are as follows:

$$
\begin{gathered}
\mathrm{NBP}=251.721( \pm 1.787)+39.416( \pm 0.347)^{\mathrm{m}} \mathrm{Xu} \\
\mathrm{N}=119 \quad \mathrm{R}^{2}=0.991 \quad \mathrm{R}_{\text {adj }}^{2}=0.991 \quad \mathrm{SE}=5.67 \quad \mathrm{~F}=12883.0 \\
\mathrm{NBP}=254.219( \pm 1.826)+40.649( \pm 0.543)^{\mathrm{m}} \mathrm{Xu}-1.381( \pm 0.209) \mathrm{AI}\left(-\mathrm{CH}_{3}\right) \\
+1.380( \pm 0.597) \mathrm{AI}(-\mathrm{O}-)
\end{gathered}
$$

It can be seen that ${ }^{\mathrm{m}} \mathrm{Xu}$ index shows good correlation with NBPs values judging from high values of $\mathrm{R}_{\text {adj }}^{2}$ and $\mathrm{F}$ and relatively low $\mathrm{SE}$. However, to obtain a more accurate model and to account the contribution of atom types or groups to the NBPs of the esters, a MLR model, added AI topological indices, was generated. Equation 4 indicates the three-parameter MLR model developed for predicting NBPs of esters. Values of the topological descriptors entered the model are given in Table 2.

As can be found, combination of ${ }^{\mathrm{m}} \mathrm{Xu}$ and $\mathrm{AI}$ indices significantly improves quality of the model. The statistics indicate that the regression explained by the model is significant at $99 \%$ confidence level and the standard error is about $20 \%$ less than SE for the simple linear model. According to the model predictions for NBPs (Table 1), maximum relative error $(2.99 \%)$ belonged to isopropyl formate. Fig. 1 demonstrates the correlation between the experimental and predicted NBPs indicating all the predicted values are within $\pm 3 \%$ error band. The results evidently proves high efficiency of the topological indices in modeling NBPs of aliphatic esters.

Table 2

Topological indices employed in the MLR model developed for NBP of aliphatic esters

\begin{tabular}{cccccccccccc}
\hline No. & ${ }^{\mathrm{m}} \mathrm{Xu}$ & $\begin{array}{c}\mathrm{AI} \\
\left(-\mathrm{CH}_{3}\right)\end{array}$ & $\begin{array}{c}\mathrm{AI} \\
(-\mathrm{O}-)\end{array}$ & $\mathrm{No}$. & ${ }^{\mathrm{m}} \mathrm{Xu}$ & $\begin{array}{c}\mathrm{AI} \\
\left(-\mathrm{CH}_{3}\right)\end{array}$ & $\begin{array}{c}\mathrm{AI} \\
(-\mathrm{O}-)\end{array}$ & No. & ${ }^{\mathrm{m}} \mathrm{Xu}$ & $\begin{array}{c}\mathrm{AI} \\
\left(-\mathrm{CH}_{3}\right)\end{array}$ & $\begin{array}{c}\mathrm{AI} \\
(-\mathrm{O}-)\end{array}$ \\
\hline 1 & 1.371 & 2.183 & 2.127 & 41 & 4.679 & 8.322 & 4.841 & 81 & 6.753 & 10.909 & 5.740 \\
2 & 1.865 & 4.637 & 2.403 & 42 & 4.566 & 11.049 & 2.916 & 82 & 6.685 & 11.296 & 4.172 \\
3 & 1.995 & 2.562 & 2.205 & 43 & 4.593 & 10.969 & 3.048 & 83 & 6.667 & 11.423 & 3.828 \\
4 & 2.595 & 2.937 & 2.494 & 44 & 4.676 & 8.299 & 3.119 & 84 & 6.534 & 13.786 & 3.682 \\
5 & 2.480 & 4.778 & 2.323 & 45 & 4.642 & 8.494 & 3.190 & 85 & 7.139 & 12.232 & 3.938 \\
6 & 2.434 & 5.440 & 2.767 & 46 & 4.592 & 11.943 & 3.091 & 86 & 7.162 & 12.058 & 4.604 \\
7 & 3.012 & 6.184 & 2.584 & 47 & 4.544 & 10.593 & 4.699 & 87 & 7.134 & 12.275 & 4.187 \\
8 & 2.946 & 7.926 & 2.374 & 48 & 4.427 & 12.76 & 2.741 & 88 & 7.134 & 12.276 & 3.952 \\
9 & 2.894 & 8.009 & 3.092 & 49 & 4.512 & 10.299 & 3.183 & 89 & 7.642 & 12.723 & 5.034 \\
10 & 3.174 & 3.311 & 2.898 & 50 & 4.474 & 12.634 & 3.042 & 90 & 7.606 & 13.017 & 4.110 \\
11 & 3.565 & 6.970 & 2.917 & 51 & 5.206 & 8.986 & 5.454 & 91 & 7.604 & 13.036 & 4.224 \\
12 & 3.634 & 6.680 & 2.794 & 52 & 5.176 & 9.154 & 4.270 & 92 & 8.067 & 13.787 & 4.332 \\
13 & 3.460 & 8.958 & 2.818 & 53 & 5.100 & 12.079 & 3.130 & 93 & 8.070 & 13.752 & 4.321 \\
14 & 3.532 & 8.847 & 2.691 & 54 & 5.280 & 8.689 & 4.046 & 94 & 8.523 & 14.529 & 4.496 \\
15 & 3.583 & 6.886 & 3.710 & 55 & 5.188 & 9.076 & 3.165 & 95 & 2.472 & 5.318 & 2.339 \\
\hline
\end{tabular}


Table 2 (continued)

\begin{tabular}{|c|c|c|c|c|c|c|c|c|c|c|c|}
\hline 16 & 3.581 & 6.897 & 2.643 & 56 & 5.163 & 9.245 & 3.219 & 96 & 3.013 & 6.177 & 3.208 \\
\hline 17 & 3.477 & 8.985 & 3.627 & 57 & 5.008 & 14.78 & 3.096 & 97 & 2.909 & 6.939 & 2.436 \\
\hline 18 & 3.475 & 8.999 & 2.540 & 58 & 5.203 & 9.000 & 3.467 & 98 & 3.456 & 8.579 & 3.369 \\
\hline 19 & 3.361 & 10.237 & 2.439 & 59 & 5.325 & 4.805 & 5.100 & 99 & 3.734 & 3.684 & 3.377 \\
\hline 20 & 3.643 & 5.896 & 3.281 & 60 & 5.037 & 13.673 & 3.399 & 100 & 3.964 & 9.732 & 3.112 \\
\hline 21 & 3.517 & 8.535 & 2.506 & 61 & 5.690 & 9.865 & 4.803 & 101 & 4.136 & 7.599 & 2.836 \\
\hline 22 & 3.306 & 10.450 & 3.378 & 62 & 5.763 & 9.478 & 4.604 & 102 & 4.099 & 9.769 & 3.084 \\
\hline 23 & 4.138 & 7.587 & 4.257 & 63 & 5.550 & 15.924 & 3.210 & 103 & 3.903 & 12.208 & 2.731 \\
\hline 24 & 4.188 & 7.369 & 3.166 & 64 & 5.720 & 9.691 & 6.090 & 104 & 4.650 & 8.440 & 3.773 \\
\hline 25 & 4.019 & 10.008 & 3.241 & 65 & 5.504 & 11.918 & 3.793 & 105 & 4.478 & 13.380 & 2.844 \\
\hline 26 & 4.113 & 7.716 & 3.319 & 66 & 5.710 & 13.311 & 4.531 & 106 & 4.543 & 6.635 & 2.695 \\
\hline 27 & 4.018 & 10.014 & 2.796 & 67 & 5.626 & 12.722 & 3.412 & 107 & 4.808 & 4.432 & 4.490 \\
\hline 28 & 4.112 & 7.720 & 2.880 & 68 & 5.718 & 9.704 & 3.868 & 108 & 5.163 & 9.242 & 3.559 \\
\hline 29 & 4.036 & 9.568 & 2.975 & 69 & 5.674 & 9.979 & 3.352 & 109 & 5.023 & 14.648 & 3.068 \\
\hline 30 & 4.042 & 9.979 & 2.751 & 70 & 6.223 & 10.399 & 6.746 & 110 & 5.700 & 9.808 & 3.446 \\
\hline 31 & 4.278 & 4.058 & 3.912 & 71 & 6.193 & 10.575 & 5.365 & 111 & 5.710 & 13.311 & 4.531 \\
\hline 32 & 4.023 & 9.408 & 2.788 & 72 & 6.220 & 10.412 & 4.312 & 112 & 5.606 & 13.15 & 3.297 \\
\hline 33 & 3.982 & 9.720 & 2.633 & 73 & 6.263 & 10.191 & 5.159 & 113 & 5.674 & 9.974 & 3.975 \\
\hline 34 & 3.863 & 11.149 & 2.579 & 74 & 6.176 & 10.697 & 4.431 & 114 & 6.168 & 10.763 & 3.579 \\
\hline 35 & 4.021 & 9.889 & 2.796 & 75 & 6.192 & 10.585 & 3.797 & 115 & 5.870 & 13.154 & 6.009 \\
\hline 36 & 4.023 & 9.408 & 2.788 & 76 & 6.168 & 10.761 & 3.857 & 116 & 6.658 & 11.497 & 4.245 \\
\hline 37 & 3.889 & 11.584 & 2.542 & 77 & 6.175 & 10.704 & 3.561 & 117 & 7.150 & 12.141 & 4.144 \\
\hline 38 & 3.959 & 9.470 & 2.663 & 78 & 5.767 & 18.771 & 2.388 & 118 & 7.612 & 12.958 & 4.200 \\
\hline 39 & 4.723 & 8.079 & 3.605 & 79 & 6.686 & 11.285 & 5.951 & 119 & 8.567 & 14.148 & 8.482 \\
\hline 40 & 4.650 & 8.447 & 2.988 & 80 & 6.655 & 11.541 & 3.378 & & & & \\
\hline
\end{tabular}

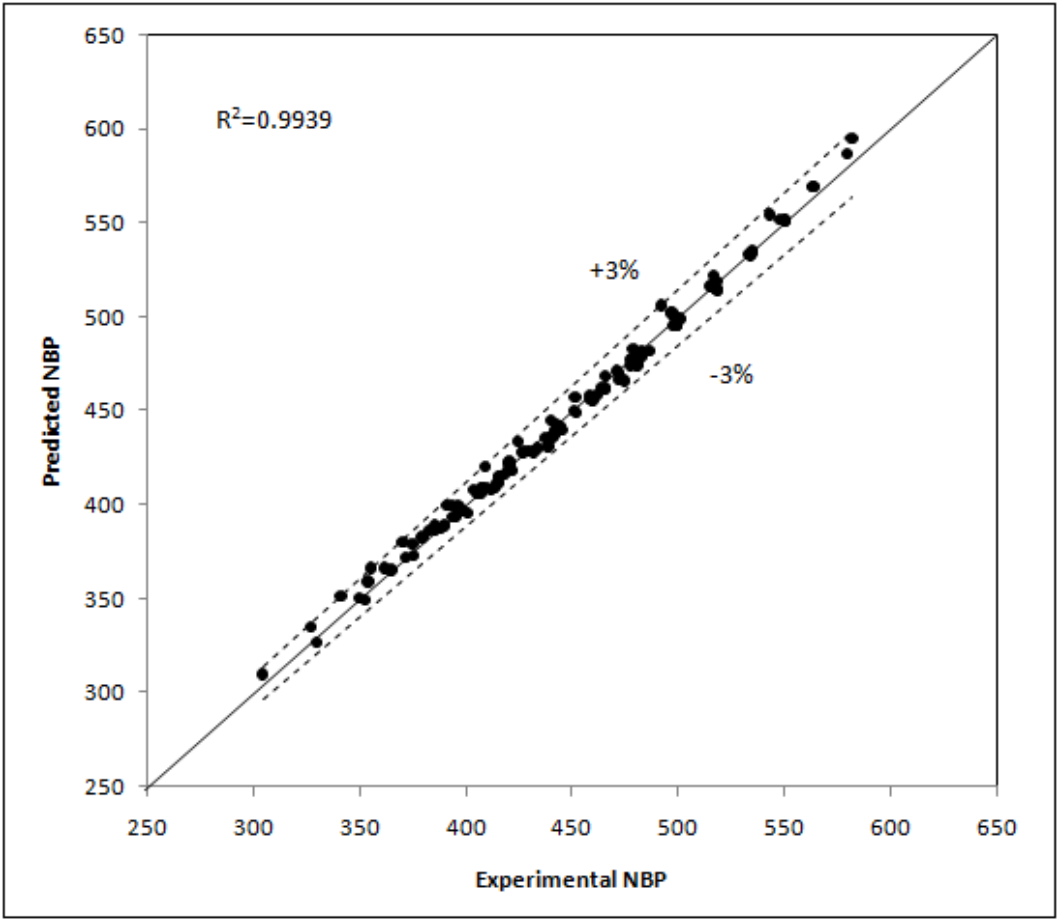

Fig. 1 - Predicted versus experimental NBPs for aliphatic esters based on the MLR model. 
Table 3

Specifications of the MLR models based on the external validation test

\begin{tabular}{llllll}
\hline & \multicolumn{5}{c}{ Training subsets } \\
\cline { 2 - 6 } Parameter & 1 & 2 & 3 & 4 & 5 \\
\hline Constant & 255.669 & 254.697 & 255.265 & 250.726 & 253.940 \\
${ }^{\mathrm{X}} \mathrm{Xu}$ & 41.025 & 40.687 & 40.599 & 40.605 & 40.199 \\
$\mathrm{AI}\left(-\mathrm{CH}_{3}\right)$ & -1.520 & -1.333 & -1.483 & -1.231 & -1.313 \\
$\mathrm{AI}(-\mathrm{O}-)$ & 0.768 & 1.054 & -1.437 & 2.085 & 1.899 \\
$\mathrm{R}^{2}{ }_{\text {adj }}$ & 0.994 & 0.994 & 0.994 & 0.995 & 0.994 \\
$\mathrm{~F}$ & 4972.4 & 5062.3 & 5381.6 & 6479.2 & 5320.9 \\
$\mathrm{SEC}$ & 4.58 & 4.53 & 4.41 & 3.98 & 4.57 \\
$\mathrm{SEP}$ & 3.84 & 4.17 & 4.67 & 6.19 & 4.02 \\
$\mathrm{n}_{\mathrm{t}} / \mathrm{n}_{\mathrm{p}}{ }^{a}$ & $95 / 24$ & $95 / 24$ & $95 / 24$ & $95 / 24$ & $96 / 23$ \\
\hline
\end{tabular}

${ }^{a} n_{t}$ and $n_{p}$ are the number of molecules in the training and prediction sets, respectively.

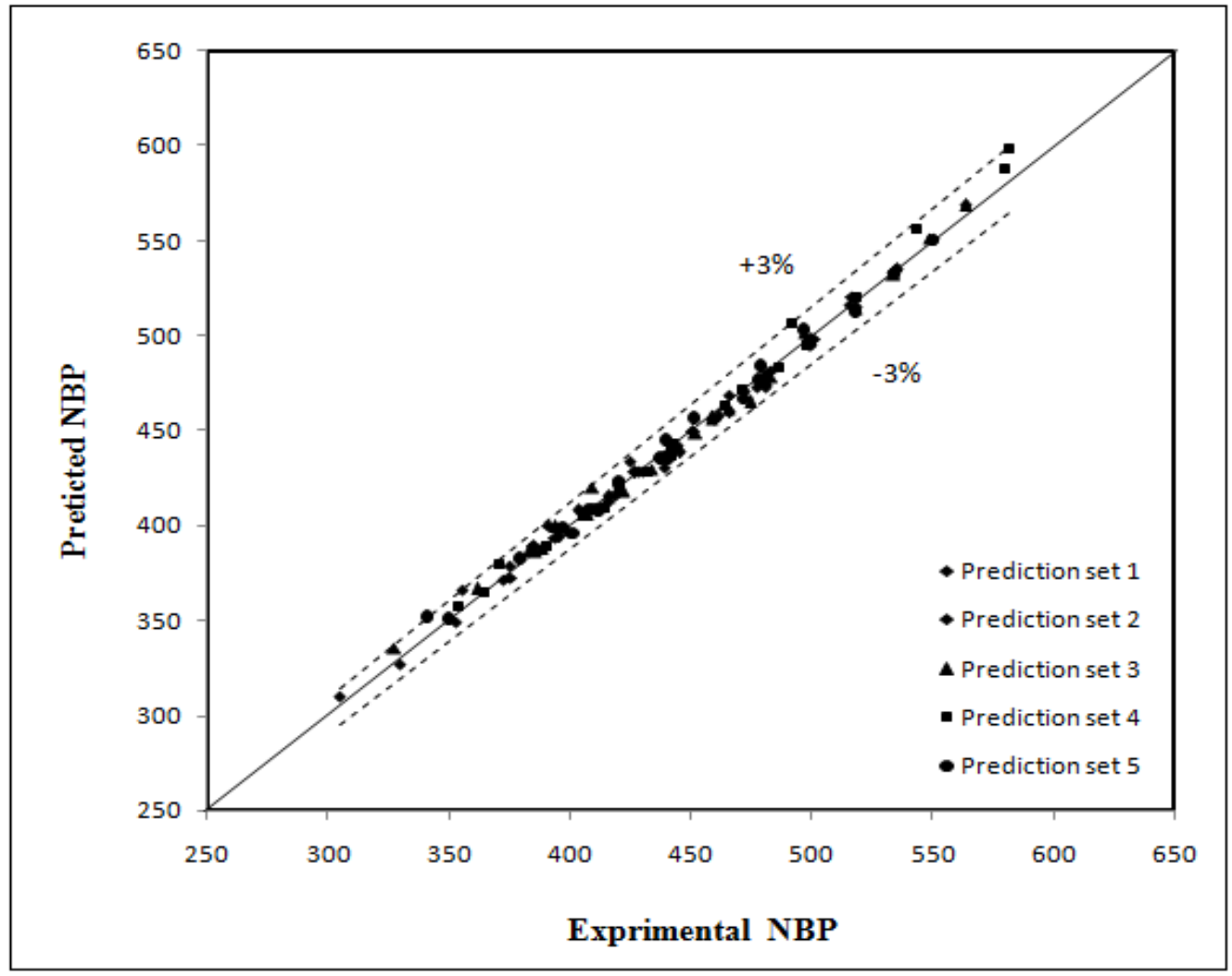

Fig. 2 - Predicted versus experimental NBPs for different prediction sets in external validation test.

Table 3 indicates the results of validation test of the MLR model. Average values of 4.58 for SEC and 4.41 for SEP show that the models developed for the training sets can satisfactorily predict NBPs for aliphatic esters not used for model generation. Good agreement between the predicted and experimental NBPs for different prediction sets can be easily observed in Fig. 2.

\section{Structural interpretation of normal boiling points of aliphatic esters}

To obtain insights into the role of the structural features of esters in determining their NBPs, the relative contribution $\left(\Psi_{\mathrm{r}}\right)$ and fraction contribution $\left(\Psi_{\mathrm{f}}\right)$ of the topological indices were calculated as follows: ${ }^{23}$

$$
\Psi_{\mathrm{r}}(\mathrm{i})=\mathrm{c}_{\mathrm{i}} \mathrm{TI}_{\mathrm{i}}
$$




$$
\Psi_{f}(\mathrm{i})=\left[\mathrm{R}^{2} \times \frac{\left|\Psi_{r}(i)\right|}{\sum_{i}\left|\Psi_{r}(i)\right|}\right] \times 100 \%
$$

where $c_{i}$ and $T I_{i}$ are the coefficient and the average value of the ith topological index entered in the MLR model and the sum is over all the topological indices. The results showed that ${ }^{\mathrm{m}} \mathrm{Xu}$ index with $\Psi_{\mathrm{f}}$ value of $91.00 \%$ is the most important descriptor appeared in the model showing that bulkiness or size of the ester molecule plays a dominant role in determining its NBP because ${ }^{\mathrm{m}} \mathrm{Xu}$ index characterizes the molecular size. $^{12}$ Relative contribution of +200.25 for this descriptor indicates that the larger the size of the molecule is, the greater its NBP. Fraction contribution values of $\mathrm{AI}\left(-\mathrm{CH}_{3}\right)$ and $\mathrm{AI}(-\mathrm{O}-)$ indices to the NBPs were $6.15 \%$ and $2.25 \%$, respectively. As expected, the relative contribution value for $\mathrm{AI}\left(-\mathrm{CH}_{3}\right)$ index was negative $\left(\Psi_{\mathrm{r}}=-13.52\right)$ because the $\mathrm{AI}\left(-\mathrm{CH}_{3}\right)$ index is clearly related to the number of methyl groups which is a crude measure of branching. ${ }^{23}$ Obviously, branching prevents close contact with neighboring molecules in space and reduces the interactions between them. Consequently, NBP decreases with increasing the $\mathrm{AI}\left(-\mathrm{CH}_{3}\right)$ index. On the other hand, positive value of +4.96 for relative contribution of $\mathrm{AI}(-\mathrm{O}-)$ index shows that higher $\mathrm{AI}(-\mathrm{O}-)$ tends to increase the extent of NBP for the aliphatic ester. This is due to the fact that the atomic - - - group belongs to the carboxyl group of ester molecules and reflects their polar character and it is no doubt that polar interactions between molecules become more important with increasing $\mathrm{AI}(-\mathrm{O}-)$ index.

\section{CONCLUSION}

In this study, an accurate three-parameter QSPR model for NBPs of a group of aliphatic esters was successfully developed using a combination of ${ }^{\mathrm{m}} \mathrm{Xu}$ index and atom-type-based AI topological indices. The MLR model is very efficient and provides satisfactory results in both accuracy and stability for predicting normal boiling point values of aliphatic esters. The results indicate that NBPs of the aliphatic esters depend not only on the molecular size but also on various atomic group of the molecules. Contribution of the topological indices included in the model decreased in the order of ${ }^{\mathrm{m}} \mathrm{Xu}>\mathrm{AI}\left(-\mathrm{CH}_{3}\right)>\mathrm{AI}(-\mathrm{O}-)$. The developed model allows prediction of NBPs for similar compounds using only the knowledge of two dimensional structure of the molecules.

\section{REFERENCES}

1. D. Ghaslani, Z. Eshagi Gorgi, A. Ebrahimipoor Gorgi and S. Riahi, Chem. Eng. Res. Des., 2017, 120, 15- 25.

2. N. Basant and Sh. Gupta, Atmos. Environ., 2018, 177, 166174

3. I. Mehraein and S. Riahi, J. Mol. Liq., 2017, 225, 521-530.

4. A. Weinebeck, S. Kaminski, H. Murrenhoff and K. Leonhard, Tribol. Int., 2017, 115, 274-284.

5. T. Nejad Ghaffar Borhani, A. Afzali and M. Bagheri, Process Saf. Environ. Prot., 2016, 103, 115-125.

6. P. Kumar and O. Kunel Roy, Food Chem. Toxicol., 2018, 112, 551-562

7. W. Zhang, J. Wu, B. Li, H. Wu, L. Wang, J. Hao, S. Wu and Q. Zhou, Org. Biomol. Chem., 2016, 14, 2840-2845.

8. N. Basant, Sh. Gupta and K.P. Singh, Neurotoxicol., 2016, 53, 45-52.

9. A. Can, Toxicol. Lett., 2014, 230, 434-443.

10. L. B. Kier and L. H. Hall, "Molecular connectivity in chemistry and drug research", New York, Academic Press, 1976.

11. L. B. Kier, L. H. Hall and J. W. Frazer, J. Math. Chem., 1991, 7, 229-241.

12. B. Ren, J. Chem. Inf. Comput. Sci., 1999, 39, 139-143.

13. B. Ren, Comput. Chem., 2002, 26, 223-235.

14. B. Ren, Comput. Chem., 2002, 26, 357-369.

15. B. Ren, J. Chem. Inf. Comput. Sci., 2003, 43, 1121-1131.

16. K. Panneerselvam, M. P. Antony, T. G. Srinivasan and P. R. V. Rao, Thermochim. Acta, 2010, 511, 107-111.

17. F. Safa and M. Yekta, Arabian J. Chem., 2017, 10, 439-447.

18. R. L. Brown and S. E. Stein, "Boiling Point Data in NIST Chemistry WebBook", Gaithersburg, National Institute of Standards and Technology, http://webbook. nist.gov, 2010.

19. SPSS version 20.0, IBM Inc, United State.

20. R. Kramer, "Chemometric techniques for quantitative analysis", New York, Marcel Dekker, 1998.

21. R.D.M.C. Amboni, B.S. Junkes, R.A. Yunes and V.E.F. Heinzen, J. Mol. Struct. (Theochem.), 2002, 586, 71-80.

22. L.B. Kier and L. H. Hall, "Molecular connectivity in structure-activity studies", Letchworth, Research Studies Press, 1986.

23. D.E. Needham, I.C. Wei and P.G. Seybold, J. Am. Chem. Soc., 1988, 110, 4186-4194. 
